\title{
Paths to Social Licence for Tracking-data Analytics
}

7

8
Joshua P. White ${ }^{1}$, Simon Dennis ${ }^{1}$, Martin Tomko², Jessica Bell ${ }^{3}$, Stephan Winter ${ }^{2}$

${ }^{1}$ Complex Human Data Hub, Melbourne School of Psychological Sciences, The University of Melbourne, Australia.

${ }^{2}$ Melbourne School of Engineering, The University of Melbourne, Australia. ${ }^{3}$ Melbourne Law School, The University of Melbourne, Australia. \section{3} 4 5 6 7 8 supported by the Networked Society Institute at the University of Melbourne.

This work is part of the Living Lab for Urban Mobility and Adaptive Space (LUMAS) project, Correspondence concerning this article should be addressed to Joshua P. White, Melbourne School of Psychological Sciences, The University of Melbourne, Redmond Barry Building, Parkville, Victoria, Australia 3010. E-mail: josh.white@unimelb.edu.au 
PATHS TO SOCIAL LICENCE FOR TRACKING-DATA ANALYTICS

26 While tracking-data analytics can be a goldmine for institutions and companies, the inherent privacy concerns also form a legal, ethical and social minefield. We present a study that seeks to understand the extent and circumstances under which tracking-data analytics is undertaken with social licence — that is, with broad community acceptance beyond formal compliance with legal requirements. Taking a University campus environment as a case, we enquire about the social licence for Wi-Fi-based trackingdata analytics. Staff and student participants answered a questionnaire presenting hypothetical scenarios involving Wi-Fi tracking for university research and services. Our results present a Bayesian logistic mixed-effects regression of acceptability judgements as a function of participant ratings on 11 privacy dimensions. Results show widespread acceptance of tracking-data analytics on campus and suggest that trust, individual benefit, data sensitivity, risk of harm and institutional respect for privacy are the most predictive factors determining this acceptance judgement.

Keywords: Social Licence, Tracking data, Acceptability, University research, Wi-Fi, location data 
PATHS TO SOCIAL LICENCE FOR TRACKING-DATA ANALYTICS

\section{Introduction}

The increased simplicity of acquiring tracking data (spatio-temporal data attached to an identifiable object or person), and their immense utility for logistics, traffic and space management, human resource management and reporting, and advertising has turned tracking-data analytics into a revenue goldmine. Yet, the inherent privacy concerns of tracking data turn them equally into a minefield.

One source for tracking data are Wi-Fi networks. Campus-based universities, shopping malls, and hospitals are examples of complex, built environments with varied stakeholders and complex logistical issues that, on one hand, operate such Wi-Fi networks, and on the other need data-driven support for efficient operations. The realisation that tracking data contain information about staff attendance, can support health and safety reporting and compliance monitoring, and inform space-use optimisation leads to an increased interest in active tracking technology deployments.

On university campuses, such data are often applied to the optimization of campus management, operations, and university services. While, these uses are often legally covered by the Wi-Fi user agreements, a failure to ensure that participants broadly accept their operation can cause negative media attention and attitudes towards the university ${ }^{1-3}$. Further, these data are also of interest for academic research from a more fundamental perspective of advancing knowledge about the applications and limits of tracking data in a variety of domains. This includes research into privacy protection ${ }^{4,5}$ and obfuscation $^{6,7}$, data cleaning and interpolation ${ }^{8,9}$, pattern detection and prediction, contact tracing ${ }^{10}$, and the integration of tracking-data with social media sentiments ${ }^{11}$ or with student or staff performance ${ }^{12}$. The use of the Wi-Fi tracking data for research purposes may not be covered in Wi-Fi user agreements, and may require additional informed consent. Wi-Fi users — the whole campus community — may feel uncomfortable with the topics, methodologies, or potential applications of some research and might thus resist having their data contribute towards them. On the other hand, many on campus might benefit from 
PATHS TO SOCIAL LICENCE FOR TRACKING-DATA ANALYTICS

more permissive use of such data through the provision of better university services and management, greater research opportunities for graduate students, and more diffuse public benefits at large.

The above affairs illustrate the importance of securing the acceptance of a university community for the tracking-data analytics operations of a university. Yet, while the legal and ethical issues about the collection and processing of these potentially privacy-encroaching technologies has received much attention, little work has empirically considered the community perception and acceptance of personal tracking in this context.

The present study seeks to understand to what extent and under what circumstances tracking-data analytics is undertaken under a social licence - i.e., with broad community acceptance beyond formal compliance with legal requirements ${ }^{13}$. Understanding the acceptance by Wi-Fi users may help (a) academics to understand sensitivities and limits in advance, (b) ethics boards with formulating policies and guidelines, (c) university governance with a realistic evaluation of user sentiments, and (d) with a broader public debate on acceptable and unacceptable use of tracking data.

Participants in our study were exposed to a questionnaire presenting hypothetical scenarios depicting the use of Wi-Fi tracking data in research and support services at the University of Melbourne, and rated these scenarios on 11 privacy dimensions that were distilled from a literature review and from a workshop of university stakeholders from a variety of disciplinary, professional and other backgrounds (see the supplementary materials and Table S4 for an in-depth description of how we derived these 11 dimensions). After making these ratings, participants indicated whether each scenario was an “acceptable" use of university tracking data.

Results show general acceptance of university research and service projects that use Wi-Fi tracking data. The results also suggest that community trust of the sponsoring institution, beliefs about their respect for people's privacy, the individual benefit conferred upon participants, the risk of harm of the project, and the sensitivity of the data being collected are the most important factors predicting this acceptance. Further, we build a predictive model to allow administrators, ethics boards, and other 
PATHS TO SOCIAL LICENCE FOR TRACKING-DATA ANALYTICS

decision-makers to foreshadow the level of community acceptance for new projects to assist their decision-making.

\section{Background}

Current wireless communication infrastructure and technology in managed environments such as university campuses, shopping malls and downtown areas allows the collection of tracking data of its users $^{14,15}$. The operators of the infrastructure will use this data for the optimization of their services, but other parties have an interest in this data as well, and some of the possible uses might be accepted by the users as useful, legitimate, or desirable. Yet, as with any technological advancement, social, ethical, and legal issues surround the data use. While infrastructure operators often focus only on satisfying the legal requirements that underlie operations, recent scholarship has emphasised the importance of going beyond this minimal threshold to technology deployment, and secure a broader basis for community acceptance

This notion — termed 'social licence to operate' — while developed primarily in the corporate social responsibility literature to describe the support and acceptance within the community of private companies' operations (particularly mining companies), has recently gained traction in the context of large-scale personal data collection and analysis. There are a number of examples of recent controversies in the healthcare sector that exemplify the degree to which a failure to secure social licence for research initiatives can undermine project success; e.g., MyHealthRecord in Australia and Care.data in the UK ${ }^{16}$. Such failures to secure social licence, however, are not limited to the healthcare sector. Indeed, the release of information about the use of $\mathrm{Wi}-\mathrm{Fi}$ and other big data in learning analytics in Australian universities has been similarly controversial and received backlash from students, regulators and the media $^{2,17,18,1}$. Such controversies have also occurred in US universities ${ }^{3,19}$, and may cause negative media attention and attitudes towards institutions, as well as negatively affect the quality of the data collected through reduced compliance or cooperation. These examples illustrate the importance of 
113 building social licence and trust amongst the community in a university and education setting if the potential benefits of use of Wi-Fi tracking data are to be realised in the future.

Extensive literature covers the ethically normative requirements for using big data in a variety of contexts $^{20,21}$, including in universities ${ }^{22}$. However, most work in relation to social licence focuses on the legal (i.e., what can entities legally do) and normative frameworks (i.e., what entities should do).

However, little work has considered the social licence for big data usage from an empirical or descriptive perspective. While there has recently been an increase in this empirical work, it has generally been limited to the social licence for big data usage in governmental services or the mining industry ${ }^{21,23-}$ 25. Here, we complement this gap by focusing on the quantitative analysis of the social licence for data use in research, in the context of data collected and analysed at Universities.

The aim of the present research is to understand the factors which affect the social licence for the use of Wi-Fi location data for research and university services. We argue that Universities are a particularly interesting environment to study from the perspective of social licence. The use of Wi-Fi location data in university research and services presents both great opportunities, but also risks. This data can be used to greatly benefit the community, by providing the ability to quickly conduct cuttingedge research with real and varied populations, the benefits of which to the community may be immense. In addition to legal requirements, institutional research ethics frameworks also govern Universities, providing extra oversight for data use. There is also a high level of collegiality amongst staff and students. For a productive and flourishing University community, it is crucial that this confidence is not undermined. Trust and confidence are particularly important because in many University institutions, individuals are a 'captive' population; individuals need to use the Wi-Fi network to effectively conduct their work and studies. As such, an individual's 'freedom' to opt-out is 137 location data use before implementation on campus. 
PATHS TO SOCIAL LICENCE FOR TRACKING-DATA ANALYTICS

To work towards a more nuanced understanding of the parameters of a social licence for the

139 research use of Wi-Fi data, in this paper we specifically address two research questions: first, which

140 scenarios for Wi-Fi location tracking do university community stakeholders find acceptable?; and

141 second, what are the factors within those scenarios that can predict this acceptability? From these

142 findings, we generalise predictive factors of community acceptability of new proposals for the collection

143 of university Wi-Fi location data. Our study has been conducted at the University of Melbourne, a 144 major, multicultural, public university in Australia. 


\section{Results}

\section{Acceptance and perception of tracking-data analytics on university campus}

After reading scenarios that depicted the use of tracking-data analytics (summarised in Table 1) participants rated them on 11 privacy dimensions (summarised in Table 2) before making a binary judgement whether the use of tracking-data analytics in each scenario was acceptable. Figure 1 shows the proportion of participants that labelled each scenario as acceptable. The mean acceptance proportion among the scenarios was $0.715(S D=0.111)$. Figures $\mathrm{S} 1$ and $\mathrm{S} 2$ show participants' perceptions of each of the scenarios in relation to each of the 11 privacy dimensions.

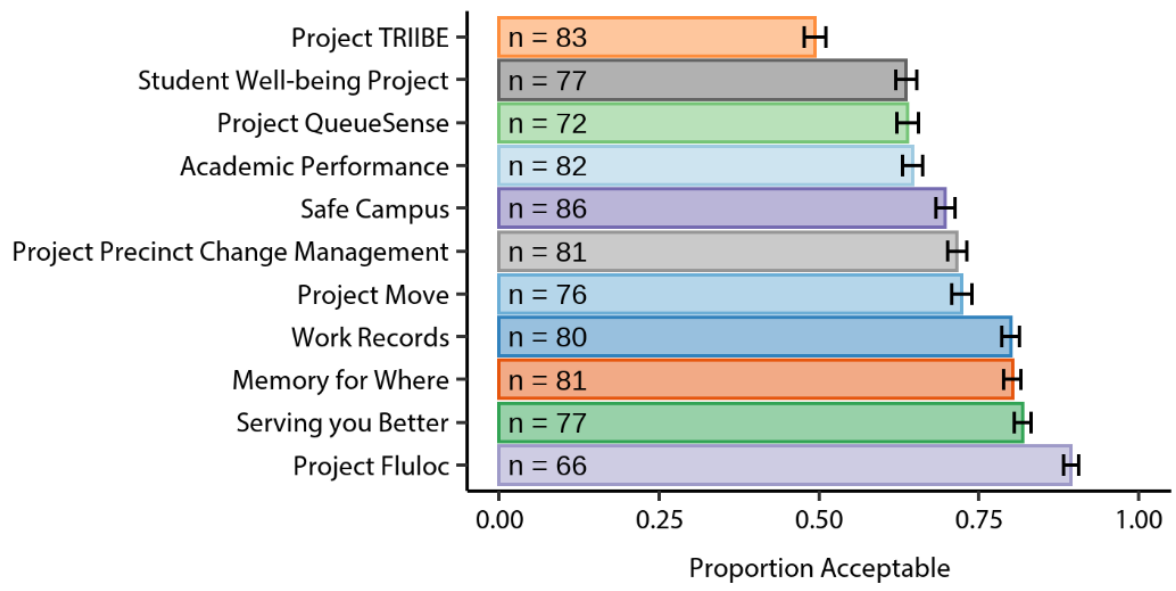

Figure 1. Participant perception of scenario acceptability. The proportion of 'acceptable' judgements for each scenario. The sample size for each scenario is listed at the base of the bar chart. Error bars represent standard errors of the mean.

\section{Predicting acceptance of tracking-data analytics on university campus}

\section{Descriptive / Explanatory Model}

Bayesian mixed effects logistic regression was used to predict participants' acceptability judgements as an additive function of their privacy dimension judgements. Two candidate models were estimated: one which included one parameter for each privacy dimension, and one which also included some a priori interaction parameters between privacy dimensions (listed in table S1).

Model selection was conducted via Pareto-smoothed importance sampling leave-one-out cross validation to maximise the out-of-sample predictive accuracy of the model ${ }^{26,27}$ and the model with the 


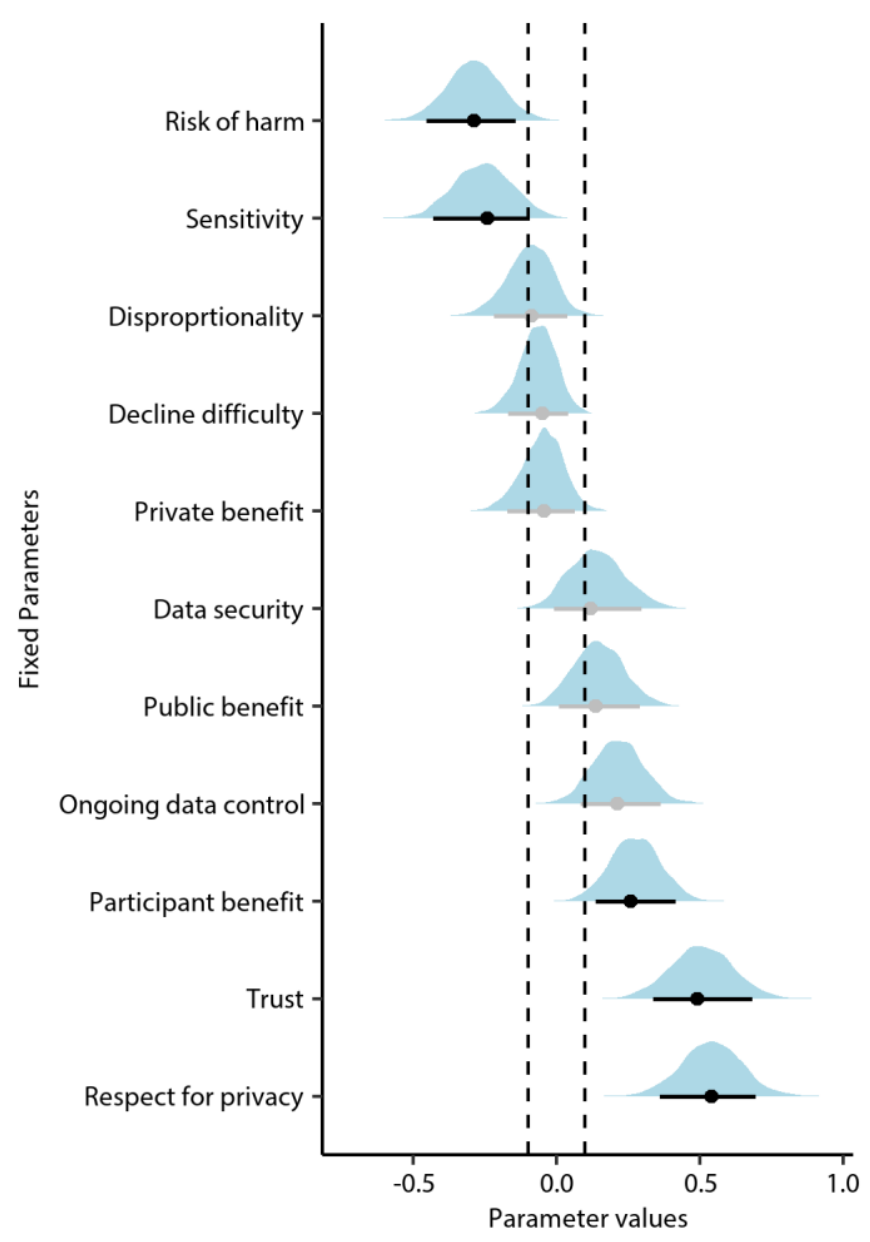

highest expected log predictive density (ELPD) was preferred. On this basis, the model without interactions $(\mathrm{ELPD}=-345.22, S E=17.54)$ was preferred to the model with interactions $(\mathrm{ELPD}=-$ 349.66, $S E=18.80)$. The preferred model had a Nakagawa conditional $R^{2}$ of $0.454(S E=0.034)$, indicating that $45.6 \%$ of the variance in the data was explained by the random and fixed predictor variables, and a Nakagawa marginal $R^{2}$ of $0.398(S E=0.024)$ indicating that $39.8 \%$ of the variance in the data is explained by the fixed predictor variables, i.e., the privacy dimension ratings ${ }^{28}$.

Figure 2. Fixed effect posterior distributions from the preferred model. Point estimates (dots) are posterior modes and intervals are $89 \%$ highest density intervals (lines). Parameters for which a practically significant effect was inferred have interval lines coloured black. The region of practical equivalence is shown between the dotted vertical lines. Practically significant effects were inferred when the entire $89 \%$ highest density interval fell outside the region of practical equivalence. 
PATHS TO SOCIAL LICENCE FOR TRACKING-DATA ANALYTICS

Posterior estimates of all fixed model parameters are shown in Figure 2 and listed in Table S2. Following the Region of Practical Equivalence (to a null effect; ROPE) + 89\% High Density Interval (HDI) decision rule, we inferred a practically relevant effect when the entire $89 \%$ HDI falls outside of the $\mathrm{ROPE}^{29,30}$. On this basis, we inferred a predictive effect on acceptability judgements for ratings of respect for privacy, trust in the research sponsor, risk of harm, participant benefit from the tracking-data analytics, and data sensitivity. The belief that the research respected people's privacy had the biggest predictive effect on acceptability judgements, with a 1-unit increase in this rating resulting in a 1.72factor increase in the odds of judging the project as acceptable. On the other hand, the smallest practically relevant effect was for the sensitivity of the data, with a 1-unit increase in this rating resulting in a 1.29-factor decrease (i.e., a 0.78 -factor increase) in the odds of judging the project as acceptable. Finally, the posterior distributions of the random intercept effects are shown in Figure S3.

\section{Predictive Model}

We also developed a predictive model to assist decision-makers to estimate the social licence of future projects. We trained 3 models on a training dataset: a logistic regression, a mixed effects logistic regression with random intercepts for scenario and participant, and an ElasticNet logistic regression with regularisation hyperparameters, $\lambda$ and $\alpha$, chosen via 10 -fold cross validation. The mixed effects logistic regression model had the best prediction accuracy $(84.31 \%)$ on the test data set when compared to the logistic regression model (83.66\%) and the ElasticNet logistic regression model (83.66\%). The regularisation hyperparameters of the ElasicNet regression were $\lambda=0$ and $\alpha=0.15$.

The preferred model — the mixed effects logistic regression — had a Cohen's Kappa of 0.61, indicating that it had 'good' or 'substantial' classification performance ${ }^{31,32}$. Table S3 shows the parameter coefficients for this model. Given privacy dimension ratings for a new project, these coefficients can be used to predict the likelihood of future acceptability judgements (via the logistic function). To facilitate the ease of this process, we have developed a simple app 
PATHS TO SOCIAL LICENCE FOR TRACKING-DATA ANALYTICS

(https://whitejp.shinyapps.io/lumas-predictive-model/) in which, after entering ratings on each dimension, a user is given a probability in return. This probability can model the percentage of the community that would accept a project with those ratings.

\section{Demographics}

Participants were 314 members of the University of Melbourne community (198 female, 111 male, 5 prefer not to say, $M_{\mathrm{age}}=25.63, S D=8.14$, range: $17-63$ years). All participants gave their informed consent prior to the experiment. Twenty-seven participants failed at least one of three comprehension checks, leaving a final sample of 287 participants (184 female, 98 male, 5 prefer not to say, $M_{\text {age }}=25.59, S D=8.21$, range: $17-63$ years $)$.

We endeavoured to match our sample to the distribution of stakeholder types (e.g. undergraduate, postgraduate, academic employee etc.) of the university. Panel E of Figure 3 shows the proportion of each type juxtaposed with the corresponding population figures taken from the University of Melbourne's 2019 Annual Report ${ }^{33}$. Our sample is representative of the students and staff of the University of Melbourne, but no population data is available for the number of other employees or others who regularly attend the university campus and our sample likely underrepresented these demographics.

Panels A-D of Figure 3 show mean participant acceptance judgements broken down by demographic variables. Omnibus ANOVA showed that mean acceptance did not differ by gender, $F(2$, $284)=0.449, p=0.638$, relationship to University of Melbourne, $F(5,281)=0.605, p=0.696$, educational attainment, $F(8,276)=0.993, p=0.441$, or age group, $F(4,276)=0.377, p=0.825$. Simple

OLS regression analysis also showed that mean acceptance did not differ by age when treated as a continuous variable, $t(279)=-0.20, p=0.844$. 

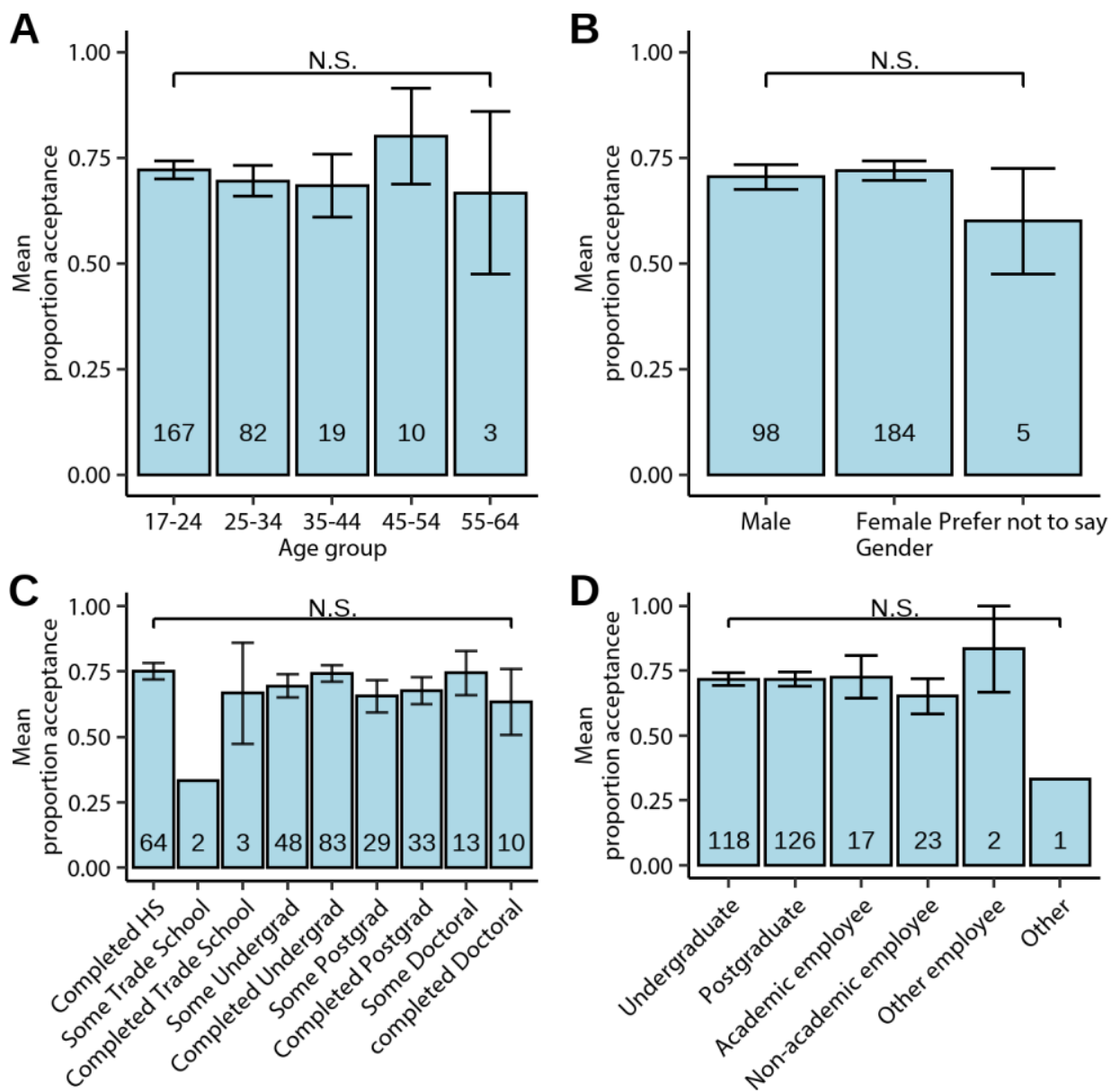

Highest educational attainment

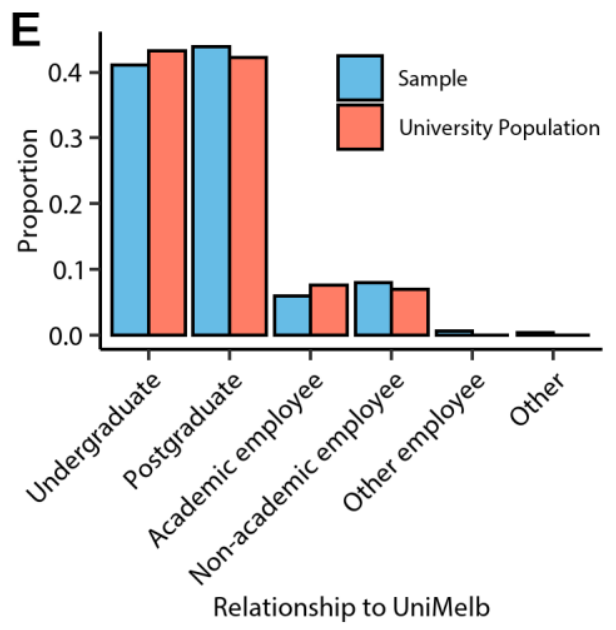

Figure 3. Acceptability of tracking-data analytics by demographics. (A-D) Mean participant acceptability proportion broken down by age group (A), gender $(\mathbf{B})$, Educational attainment $(\mathbf{C})$, and relationship to the University of Melbourne (D). Acceptability ratings did not differ by any of these demographic variables. Numbers at the bottom of the bars indicate the sample size in that group. (E) The proportion of participants in our sample (blue) from each 'relationship to UniMelb' category compared to that of the university population (red). Note, no population data was obtained for 'other employee' or 'other' categories. 
PATHS TO SOCIAL LICENCE FOR TRACKING-DATA ANALYTICS

\section{Discussion}

In this study we aimed to explore and understand the social licence, or lack thereof, for the use of Wi-Fi location data in university research and service provision. More specifically, we sought to understand whether, to what extent, and under what circumstances, there is social license for location data collection and use. To answer these questions, we presented participants - members of the University of Melbourne community (students, staff, and others) — with 11 hypothetical scenarios depicting the use of Wi-Fi location data on campus. We asked them to rate these scenarios in relation to 11 privacy dimensions, and finally to indicate whether they believed that the use of data in the scenario was acceptable. We then used participants ratings on these 11 privacy dimensions to predict participant attitudes of acceptability, hoping to understand which dimensions are most predictive of social licence.

\section{Establishing the social licence for tracking-data analytics}

Our data generally support the notion that, for the hypothetical projects used in this study, there is wide support for the use of University Wi-Fi location data in University research and services. Indeed, the mean acceptance proportion of the scenarios was 71.5\%. and all but one (Project TRIIBE) gained more than $50 \%$ acceptance. However, social licence is not conceptualised as merely a majoritarian enterprise but rather as requiring the broad support of the community ${ }^{34}$. Yet, even incorporating a higher acceptance criterion, our data is promising: four of the scenarios (Work Records, Memory for Where, Serving you Better, and Project Fluloc) exceeded $80 \%$ acceptability. Of course, exactly where the acceptability criterion should be set by decision-makers as the minimum to establish social licence is likely to depend on contextual factors, and is beyond the scope of this research.

Another consideration relevant to establishing social licence is not just the degree of acceptance of a project, but also how this acceptance is distributed; that is, support for a project must be manifest across the various constituent groups of a community ${ }^{35}$. Here, our results are promising: acceptability judgements did not differ as a function of gender, age, or educational attainment, suggesting that the 
PATHS TO SOCIAL LICENCE FOR TRACKING-DATA ANALYTICS

acceptance of tracking-data analytics is not just concentrated to a few groups. Most relevantly, there were also no differences in acceptance judgements between staff (both academic and non-academic) and students (both under- and post-graduate). Given the different interests and incentives between these groups, it was perhaps surprising that acceptance ratings did not differ ${ }^{34}$.

\section{Factors predicting social licence}

Our results also give insight into the factors which are most predictive of social licence. Here, we find evidence that the most predictive factors in determining the social licence for tracking-data analytics on the university of Melbourne campus is the perception that the research team respects individual privacy, the trust in the research team, the degree to which people personally benefit from the project, the sensitivity of the data being collected and used, and the risk of harm inherent in the project. Surprisingly, however, the perception of the public benefit of a project did not show strong evidence of increasing the likelihood of project acceptability, nor did the perception of private or commercial benefit; only a personal benefit did. Thus, clearly identifiable and more imminent benefits that flow directly to those whose data are being collected and used, are more likely to increase social licence than more diffuse, amorphous public benefits.

Our findings also suggest limited predictive ability of a one-time opt-in/opt-out distinction on acceptability. Indeed, we found that perceptions of the initial difficulty of declining to have one's data collected and used in a project was less strongly predictive of acceptance than perceptions of how much ongoing control over their data users had (e.g., control over how and when one's data was collected, and personal ability to view and delete their data). This may have implications for privacy law which, in Australia and often elsewhere, considers consent as a requirement, not ongoing control of data ${ }^{36}$.

Finally, the strong effect of trust in increasing the likelihood of acceptance is in line with previous work which suggested that trust was the primary factor underlying social licence for a proposed coal seam gas mine ${ }^{37}$. Similarly, the strong effect for 'respect for privacy' shows how acceptance of 
PATHS TO SOCIAL LICENCE FOR TRACKING-DATA ANALYTICS

privacy-encroaching technologies relates to peoples' perceptions of how such technologies affect their privacy. As such, our findings are broadly in line with the notion that people undertake a privacy calculus in which they weigh the benefits of a technology with the negatives and risks of their privacy being compromised ${ }^{38}$.

\section{Estimating the social licence of future projects}

We further provide a simple approach to estimate the social licence of future projects that may be of use to university ethics boards or decision makers. We have built a forward-looking predictive regression model which takes ratings of a university project that involves location data collection and analytics on 11 dimensions and predicts what proportion of the university community, given those ratings, will consider the project acceptable. Decision makers could use this to estimate the social licence for their proposed projects. To best do so, decision makers could get a small sample of independent ratings for their project on the 11 dimensions, take the mean rating for each dimension, and input these into the model to obtain an estimate of the proportion of community members who would likely view the scenario as acceptable, given the scenario ratings. To facilitate this, we have created an online app (https://whitejp.shinyapps.io/lumas-predictive-model/). This ability to prospectively estimate social licence will allow decision-makers to either drop projects with little prospect of community support, or to make changes to project details (that are reflected by altered independent ratings on the 11 dimensions) to increase community acceptability.

\section{Limitations}

We should be careful to extend these findings too far beyond the university domain. In particular, we should be careful to generalise to significantly different contexts such as government surveillance for which there are specific considerations and a large literature ${ }^{39-42}$. Future work should consider the social licence for tracking-data use and collection in a wider context and sample ${ }^{43,44}$. Crucially, social licence 
PATHS TO SOCIAL LICENCE FOR TRACKING-DATA ANALYTICS

312

313

requires openness and transparency to inspire trust and confidence in uses of data. The authors' note with emphasis that social licence is highly context dependent, and hope that the innovative methodological process described in this paper can be used to help uncover trustworthy uses of data in a given context, as part of an open dialogue with those who provide the data in the first instance. While the methodology offers a process for predicting acceptable uses, it is not a panacea but an additional tool in the suite of governance mechanisms for trustworthy data use.

\section{Conclusion}

These findings show that a large majority of the University of Melbourne community find the hypothetical scenarios presented to them acceptable. Further, our research suggests that trust of the research sponsor, the belief that they respect people's privacy, the benefit to participants of the research or service, and the sensitivity of the data collected, and the risk of harm imposed by the research, are all important factors which help determine the social licence of tracking-data analytics. Researchers, university management, and those collecting location and other sensitive data, could use these results to cater their data collection and analytics methodology to community commands and expectations. Indeed, doing so will generally increase the efficacy of the data collection and avoid pushback, protest and negative publicity ${ }^{45}$ that may arise from inadvertently stepping out of their social licence.

Considerations of the social licence of tracking-data analytics are only likely to grow in coming years as tracking-data collection and analysis methodologies become easier and more pervasive, and as a result of the widespread uptake of privacy-encroaching tracking technologies by governments around the world in response to the COVID-19 pandemic $^{43,44,46}$. 
PATHS TO SOCIAL LICENCE FOR TRACKING-DATA ANALYTICS

\section{Stimuli and Apparatus}

\section{Scenarios}

Stimuli were 11 hypothetical scenarios, each of which described a project involving the use of Wi-Fi location data on the University of Melbourne campus. All 11 scenarios are reproduced in full in the supplementary methods and materials, but a summary of each is shown in Table 1.

\section{Privacy Dimensions}

Participants rated these scenarios in relation to 11 privacy dimensions on a 0-5 Likert scale. Table 2 is a list of these dimensions, the question posed to participants in relation to each dimension, and the labels used for its Likert scale. Only the most extreme points of the Likert scale were defined, and a slider bar was used between these points.

These 11 privacy dimensions were developed from an extensive literature review and a workshop event in which University of Melbourne Stakeholders including students, academics (from Law, Engineering, Computer Science and Psychology) and professional staff from University Services 'brainstormed' the relevant privacy and acceptability dimensions that may affect social licence. The literature review considered research that examined the dimensions underlying ethical tracking-data collection and use from both a normative $\mathrm{e}^{20,47,48}$ and descriptive/empirical perspective, both qualitative $\mathrm{e}^{21}$ and quantitative $\mathrm{e}^{23-25}$. The final 11 dimensions were drawn qualitatively from an analysis of these sources. For further details of this process, please see the supplementary methods and table S4.

\section{Apparatus}

The above stimuli were presented to participants on their own electronic devices through their web-browser, via a survey scripted through Qualtrics.

\section{Procedure}

Participants were instructed that they were going to be shown 3 scenarios that they should read carefully. These 3 scenarios were randomly drawn from the list of 11 scenarios and shown to them 
PATHS TO SOCIAL LICENCE FOR TRACKING-DATA ANALYTICS

358

359

360

361

sequentially. For each scenario, participants were given an attention check question which asked, "What was the previous scenario about?". There were 4 randomly ordered response options to this question: the correct answer for the scenario they had just read, and 3 decoy answers drawn randomly from the correct answers for the other scenarios. Participants that failed at least one of these attention check questions were excluded from analysis.

Participants were then asked to rate each scenario on a $0-5$ Likert scale in relation to the 11 privacy dimensions. Participants rated each of their 3 randomly drawn scenarios contemporaneously on each dimension to allow for comparative scaling. While doing so, participants were provided with the scenario text below for them to refer to if necessary. The dimensions were presented to participants in the top-bottom order indicated in Table 2. After rating each scenario on each dimension, participants were asked 'whether the proposed use of university data in each scenario was acceptable' and gave a binary yes/no response. Finally, participants were asked some demographic questions: their age, gender, educational attainment, and their relationship to the University of Melbourne.

\section{Statistical Analysis}

\section{Descriptive Model}

Bayesian generalised linear mixed modeling (GLMM) was used to predict participant's acceptability judgements as an additive function of their privacy dimension judgements. Random intercept effects were included in the model to account for the dependency of the data introduced by different participants rating different scenarios. Thus, all random effects were blocked by participant and scenario. These random effects can be thought of as modelling the acceptability that is inherent in the participant or scenario that is not captured in the model's fixed parameters (the privacy dimension ratings and interactions therebetween). The privacy dimension Likert ratings were treated as numeric data for the purposes of modeling. The best-fitting model was also estimated with monotonic effects that preserve the ordinal nature of the Likert ratings ${ }^{49}$. This model performed worse for out-of-sample 
PATHS TO SOCIAL LICENCE FOR TRACKING-DATA ANALYTICS

383

384

385

386

387

388

389

390

391

392

393

394

395

396

397

398

399

400

401

402

403

404

405

406

407

predictive accuracy (see supplementary materials), providing support for treating these Likert ratings as numeric in all the analyses reported in this paper.

Posterior distributions of model parameters were estimated using Hamiltonian Markov Chain Monte Carlo No-U-turn Sampling implemented in the R package $b_{r m s}{ }^{50}$, a high level interface to $\operatorname{Stan}^{51}$. Four chains with 2000 iterations (including 1000 'burn-ins') were used. Uninformative priors were used for the intercept and random effect standard deviation parameters; both were Cauchy distributed with a location parameter of 0 and a scale parameter of $2.5^{52,53}$. Weakly informative priors were used for all fixed effect coefficients: a Laplacian (double exponential) distribution with a location parameter of 0 and a scale parameter of 0.2 (1/ range).

We developed two plausible candidate models: one which included one parameter for each privacy dimension, and one which also included some a priori interaction parameters between privacy dimensions (see Table S1). Model selection between these models was conducted via Pareto-smoothed importance sampling leave-one-out cross validation using the loo package ${ }^{27}$ in $\mathrm{R}$ : the model with the highest expected log predictive density (ELPD) was preferred.

To make inferences about the existence of effects, we used the Region of Practical Equivalence (to a null effect; ROPE) $+89 \%$ High Density Interval (HDI) decision rule: infer an effect if the entire $89 \%$ HDI falls outside of the ROPE ${ }^{29,30}$. The region of practical equivalence was deemed to be any effect that causes less than a 5\% increase or decrease from the mean acceptability proportion over the entire range of the variable. In this case, the ROPE was thus \pm 0.098 .

\section{Predictive Model}

Data was randomly split into a training (80\%) and testing set (20\%) grouped by participant so that no participant's data was used in both training and testing. 3 models were fit on the training dataset via maximum likelihood estimation and then evaluated on the test dataset, using classification accuracy as the model selection metric. The logistic regression and the mixed effects logistic regression were 
PATHS TO SOCIAL LICENCE FOR TRACKING-DATA ANALYTICS

408 estimated with $\operatorname{lme}^{4^{\mathbf{5 4}}}$. ElasticNet logistic regression was conducted using caret $^{\mathbf{5 5}}$ and glmnet $^{\mathbf{5 6}}$. 5-repeat 409 10-fold cross validation was used to tune regularization hyperparameters, $\alpha$ and $\lambda$, via a grid search (all 410 combinations of $\alpha$ and $\lambda$ for $A=\{0,0.05,0.1, \ldots 1\}$ and $\Gamma=\{0,0.05,0.1, \ldots 2\})$, again using 411 classification accuracy as the metric. For prediction in the test dataset, the random intercepts from the 412 mixed effects model were dropped, and only fixed effects were used. 
PATHS TO SOCIAL LICENCE FOR TRACKING-DATA ANALYTICS

\section{References}

1. Xiao, A. University rejects outrage over mobile phone tracking. Australian Broadcasting Corporation (2020).

2. Cook, H. University students, you are being watched. The Age (2016).

3. Harwell, D. Colleges are turning students' phones into surveillance machines, tracking the locations of hundreds of thousands. Washington Post (2019).

4. Veale, M., Binns, R. \& Ausloos, J. When data protection by design and data subject rights clash. Int. Data Priv. Law 8, 105-123 (2018).

5. Cunche, M. I know your MAC address: targeted tracking of individual using Wi-Fi. J. Comput. Virol. Hacking Tech. 10, 219-227 (2014).

6. Krumm, J. A survey of computational location privacy. Pers. Ubiquitous Comput. 13, 391-399 (2009).

7. Ardagna, C. A., Cremonini, M., Damiani, E., De Capitani di Vimercati, S. \& Samarati, P. Location Privacy Protection Through Obfuscation-Based Techniques. in Data and Applications Security XXI (eds. Barker, S. \& Ahn, G.-J.) 47-60 (Springer, 2007). doi:10.1007/978-3-540-73538-0_4.

8. Zou, H., Chen, Z., Jiang, H., Xie, L. \& Spanos, C. Accurate indoor localization and tracking using mobile phone inertial sensors, WiFi and iBeacon. in 2017 IEEE International Symposium on Inertial Sensors and Systems (INERTIAL) 1-4 (2017). doi:10.1109/ISISS.2017.7935650.

9. Sapiezynski, P., Stopczynski, A., Gatej, R. \& Lehmann, S. Tracking Human Mobility Using WiFi Signals. PLOS ONE 10, e0130824 (2015).

10. How To Use Wi-Fi Networks To Ensure a Safe Return to Campus - IEEE Spectrum. IEEE Spectrum: Technology, Engineering, and Science News https://spectrum.ieee.org/view-from-thevalley/telecom/wireless/want-to-return-to-campus-safely-tap-wifi-network. 
PATHS TO SOCIAL LICENCE FOR TRACKING-DATA ANALYTICS

11. Ciuccarelli, P., Lupi, G. \& Simeone, L. Visualizing the Data City: Social Media as a Source of Knowledge for Urban Planning and Management. (Springer International Publishing, 2014). doi:10.1007/978-3-319-02195-9.

12. Scanlon, P. \& Smeaton, A. F. Using WiFi Technology to Identify Student Activities Within a Bounded Environment. in Data Driven Approaches in Digital Education (eds. Lavoué, É., Drachsler, H., Verbert, K., Broisin, J. \& Pérez-Sanagustín, M.) 473-478 (Springer International Publishing, 2017). doi:10.1007/978-3-319-66610-5_45.

13. Boutilier, R. G. Frequently asked questions about the social licence to operate. Impact Assess. Proj. Apprais. 32, 263-272 (2014).

14. Ren, Y., Tomko, M., Salim, F. D., Ong, K. \& Sanderson, M. Analyzing Web behavior in indoor retail spaces. J. Assoc. Inf. Sci. Technol. 68, 62-76 (2017).

15. Ren, Y., Tomko, M., Salim, F. D., Chan, J. \& Sanderson, M. Understanding the predictability of user demographics from cyber-physical-social behaviours in indoor retail spaces. EPJ Data Sci. 7, $1-21(2018)$.

16. Carter, P., Laurie, G. T. \& Dixon-Woods, M. The social licence for research: why care.data ran into trouble. J. Med. Ethics 41, 404-409 (2015).

17. The Australian Broadcasting Corporation. University of Melbourne defends wi-fi tracking as planning move amid privacy concerns. ABC News (2016).

18. The University of Melbourne. University statement on Wifi analysis on campus. The Univerisity of Melbourne Newsroom https://about.unimelb.edu.au/newsroom/news/2016/august/universitystatement-on-wifi-analysis-on-campus (2016).

19. Mogg, T. Alabama University Tracks Students to See If They Leave Football Games. Digital Trends (2019).

20. Ballantyne, A. Where is the human in the data? A guide to ethical data use. GigaScience 7, (2018). 
PATHS TO SOCIAL LICENCE FOR TRACKING-DATA ANALYTICS

460

461

462

463

464 465

466

467

468

469

470

471

472

473

474

475

476

477

478

479

480

481

482

483

21. Gulliver, P., Jonas, M., McIntosh, T., Fanslow, J. \& Waayer, D. Qualitative research: Surveys, social licence and the integrated data infrastructure. Aotearoa N. Z. Soc. Work 30, 57 (2018).

22. Prinsloo, P. \& Slade, S. Student data privacy and institutional accountability in an age of surveillance. in Using Data to Improve Higher Education 195-214 (2014).

23. Data Futures Partnership. A path to social license: Guidelines for trusted data use. (2017).

24. Data Futures Partnership. Our data, our way: What New Zealand people expect from guidelines for data use and sharing. (2017).

25. Boutilier, R. G. A Measure of the Social License to Operate for Infrastructure and Extractive Projects. https://papers.ssrn.com/abstract=3204005 (2017) doi:10.2139/ssrn.3204005.

26. Vehtari, A., Simpson, D., Gelman, A., Yao, Y. \& Gabry, J. Pareto Smoothed Importance Sampling. ArXiv150702646 Stat (2019).

27. Vehtari, A., Gelman, A. \& Gabry, J. Practical Bayesian model evaluation using leave-one-out crossvalidation and WAIC. Stat. Comput. 27, 1413-1432 (2017).

28. Nakagawa, S. \& Schielzeth, H. A general and simple method for obtaining R2 from generalized linear mixed-effects models. Methods Ecol. Evol. 4, 133-142 (2013).

29. Kruschke, J. K. Rejecting or Accepting Parameter Values in Bayesian Estimation: Adv. Methods Pract. Psychol. Sci. (2018) doi:10.1177/2515245918771304.

30. Kruschke, J. K. \& Liddell, T. M. The Bayesian New Statistics: Hypothesis testing, estimation, metaanalysis, and power analysis from a Bayesian perspective. Psychon. Bull. Rev. 25, 178-206 (2018).

31. Fleiss, J. L., Levin, B. \& Paik, M. C. Statistical Methods for Rates and Proportions. (John Wiley \& Sons, 2013).

32. Landis, J. R. \& Koch, G. G. The Measurement of Observer Agreement for Categorical Data.

Biometrics 33, 159-174 (1977).

33. The University of Melbourne. University of Melbourne 2019 Annual Report. (2019). 
PATHS TO SOCIAL LICENCE FOR TRACKING-DATA ANALYTICS

34. Wilburn, K. M. \& Wilburn, R. Achieving social license to operate using stakeholder theory. J. Int. Bus. Ethics 4, 3-16 (2011).

35. Gunningham, N., Kagan, R. A. \& Thornton, D. Social License and Environmental Protection: Why Businesses Go Beyond Compliance. Law Soc. Inq. 29, 307-341 (2004).

36. Parliament of the Commonwealth of Australia. Privacy Act 1988 (Cth), Schedule 1 (Australian Privacy Principles).

37. Moffat, K. \& Zhang, A. The paths to social licence to operate: An integrative model explaining community acceptance of mining. Resour. Policy 39, 61-70 (2014).

38. Dienlin, T. \& Metzger, M. J. An Extended Privacy Calculus Model for SNSs: Analyzing SelfDisclosure and Self-Withdrawal in a Representative U.S. Sample. J. Comput.-Mediat. Commun. 21, $368-383$ (2016).

39. Nam, T. What determines the acceptance of government surveillance? Examining the influence of information privacy correlates. Soc. Sci. J. (2018) doi:10.1016/j.soscij.2018.10.001.

40. Nam, T. Untangling the relationship between surveillance concerns and acceptability. Int. J. Inf. Manag. 38, 262-269 (2018).

41. Nam, T. Does ideology matter for surveillance concerns? Telemat. Inform. 34, 1572-1585 (2017).

42. Friedewald, M., Burgess, J. P., Čas, J., Bellanova, R. \& Peissl, W. Surveillance, Privacy and Security: Citizens’ Perspectives. (Taylor \& Francis, 2017).

43. Paul M. Garrett et al. The acceptability of smartphone tracking technologies for COVID-19 in Australia. (2020).

44. Lewandowsky, S. et al. Public acceptance of Privacy-Encroaching Policies to Address the COVID19 Pandemic in the United Kingdom. (2020).

45. Franks, D. M. et al. Conflict translates environmental and social risk into business costs. Proc. Natl. Acad. Sci. 111, 7576-7581 (2014). 
PATHS TO SOCIAL LICENCE FOR TRACKING-DATA ANALYTICS

46. Oliver, N. et al. Mobile phone data for informing public health actions across the COVID-19 pandemic life cycle. Sci. Adv. 6, eabc0764 (2020).

47. Marx, G. T. Ethics for the New Surveillance. Inf. Soc. 14, 171-185 (1998).

48. Pounder, C. N. M. Nine principles for assessing whether privacy is protected in a surveillance society. Identity Inf. Soc. 1, 1-22 (2008).

49. Bürkner, P.-C. \& Charpentier, E. Modelling monotonic effects of ordinal predictors in Bayesian regression models. Br. J. Math. Stat. Psychol. n/a,.

50. Bürkner, P.-C. brms: An R Package for Bayesian Multilevel Models Using Stan. J. Stat. Softw. 80, $1-28$ (2017).

51. Carpenter, B. et al. Stan: A Probabilistic Programming Language. J. Stat. Softw. 76, 1-32 (2017).

52. Gelman, A. Prior distributions for variance parameters in hierarchical models (comment on article by Browne and Draper). Bayesian Anal. 1, 515-534 (2006).

53. Gelman, A., Jakulin, A., Pittau, M. G. \& Su, Y.-S. A weakly informative default prior distribution for logistic and other regression models. Ann. Appl. Stat. 2, 1360-1383 (2008).

54. Bates, D., Mächler, M., Bolker, B. \& Walker, S. Fitting linear mixed-effects models using lme4. J. Stat. Softw. 67, 1-48 (2015).

55. Kuhn, M. Building Predictive Models in R Using the caret Package. J. Stat. Softw. 28, 1-26 (2008).

56. Friedman, J. H., Hastie, T. \& Tibshirani, R. Regularization Paths for Generalized Linear Models via Coordinate Descent. J. Stat. Softw. 33, 1-22 (2010). 
PATHS TO SOCIAL LICENCE FOR TRACKING-DATA ANALYTICS

\section{Acknowledgments}

The authors would like to thank all members of the University of Melbourne community that participated in the LUMAS Social Licence Workshop which helped refine and conceive the idea and methods for this research. We would also like to thank the participants who completed the experiment forming the basis of this paper.

Funding: This research is part of the LUMAS project, funded by the Networked Society Institute at the University of Melbourne.

Author contributions: S.D., J.B., M.T. and S.W. conceived the research. J.B. and S.D. led the workshop which contributed to the methodology. J.P.W. completed the initial literature review. S.D. and J.P.W. designed the methodology. J.P.W created the survey, collected and analysed data (with advice from S.D.) and prepared the initial draft of the manuscript. All authors reviewed and edited drafts to create final manuscript.

Competing interests: There are no competing interests.

Data and materials availability: All data needed to evaluate the conclusions in the paper are present in the paper and/or the Supplementary Materials. The complete data and code for reproducing the results in this article are available on the Center for Open Science website https://osf.io/mx948/, doi:10.17605/OSF.IO/MX948. 
Table 1. Summary of scenarios presented to participants.

\begin{tabular}{ll} 
Scenario Name & \multicolumn{1}{c}{ Scenario Summary } \\
\hline Work Records & $\begin{array}{l}\text { University services develop a web-based platform to enable workers on campus to log } \\
\text { their working hours and track their working locations through Wi-Fi data, allowing } \\
\text { the University to improve service quality and worker safety. Workers usage of the } \\
\text { web-based platform is compulsory. }\end{array}$ \\
Memory for Where $\quad \begin{array}{l}\text { Researchers collect participants' location via University Wi-Fi data, and later } \\
\text { undertake an experiment in which participants recall where they were at certain times. } \\
\text { This research seeks to understand people's memory for location and determine what } \\
\text { factors influence the errors they make. Participants must opt-in to the study and are } \\
\text { paid } \$ 50 \text { for their data and } \$ 15 \text { for completing the memory experiment. }\end{array}$
\end{tabular}

Serving you Better The University uses Wi-Fi location data and analysis techniques to monitor the use of university food outlets and common areas to better understand the factors that drive the use of these facilities, and how to provide students with a better university experience. No analysis of individual patterns will be undertaken, only aggregated statistical trends. Students can opt-out of the project if they wish.

Safe Campus

Academic researchers collaborate with a start-up firm to use university Wi-Fi data to develop a smartphone app that allows people to be matched with 'walking buddies' to keep them safe at night on campus.

Student Wellbeing Project

The University uses student data, including their W-Fi location data, in a learning analytics system to help improve mental health and identify at-risk students. Students must opt in to participate, and are paid \$20 for doing so.

Project Move

The University collaborates with Yarra Trams to use university Wi-Fi location and timetable data to improve public transport availability and provide information about likely wait-times and occupancy.

Project TRIIBE University campus shopping and food retailers, collaborating with researchers, use location and internet history data to develop methods to capture and analyse indoor shopping behaviour across shoppers' physical, online, and social environments, to improve customer experience. Participants are paid $\$ 100$ for their data and must opt in to participate.

Project QueueSense Researchers collect Wi-Fi location data at select locations on campus (such as café outlets) to develop algorithms to reduce queueing times at these locations. Coffee will be discounted during the 1-month period of data collection

Project Fluloc

University researchers collect data of social interactions based on indoor Wi-Fi tracking and online health questionnaire data, to assess the role of professional and educational environments in the spread of influenza.

Project Precinct University researchers, collaborating with University Services and the Facilities Change Management Management Metro, develop algorithms and computational methods to understand the impact of construction disturbances on campus operations and develop methods for improved space use.

Impact of Attendance Researchers use Wi-Fi location data to track a cohort of students for one semester to on Academic understand how university attendance and presence affects academic and other Performance outcomes. 
Table 2. Summary of privacy dimensions on which each scenario was rated.

Dimension

Question

Likert response

Decline Difficulty

How easy is it for people to decline participation in the proposed research?

How much would private entities benefit from the proposed research?

How much would participants (i.e., the people

Participant Benefit

Public Benefit

Disproportionality

Sensitivity

Risk of Harm

Trust

Data Security

Ongoing Control

Respect for Privacy whose data is being collected) benefit from the proposed research?

How much would the public benefit from the proposed research?

To what extent are the researchers only collecting the data necessary to achieve the purposes of the proposed research?

How sensitive is the data to be collected by the proposed research?

How serious is the risk of harm that could arise from the proposed research?

How much do you trust the sponsor of the proposed research?

How secure is the data that would be collected from the proposed research?

To what extent do participants have ongoing control of their data? This includes controlling how and when data is collected, and having access to view and delete data after it is collected.

To what extent do you believe the proposed research respects participants' privacy?
$0=$ 'Extremely easy'

$5=$ 'Extremely difficult'

$$
\begin{gathered}
0={ }^{\prime} \text { Not at all' } \\
5=\text { 'Extremely' }
\end{gathered}
$$

$0=$ 'Not at all'

$5=$ 'Extremely'

$0=$ 'Not at all'

$5=$ 'Extremely'

$0=$ 'Researchers collecting only necessary data'

$5=$ 'Researchers collecting vast amounts of unnecessary data'

$0=$ 'Not at all sensitive' $5=$ 'Very sensitive'

$0=$ 'Extremely low risk of harm' $5=$ 'Extremely high risk of harm'

$$
\begin{gathered}
0={ }^{'} \text { Not at all' } \\
5={ }^{\prime} \text { Extremely' }
\end{gathered}
$$

$0=$ 'Not at all secure'

$5=$ 'Extremely secure'

$0=$ 'No control at all'

$5=$ 'Complete Control'

$$
\begin{gathered}
0={ }^{\prime} \text { Not at all' } \\
5=\text { 'Extremely' }
\end{gathered}
$$




\section{Supplementary Materials}

\section{$550 \quad$ Materials and Methods}

\section{$551 \quad$ Scenarios}

552 Below we reproduce the final scenarios in full as presented to participants.

\section{Project Title: Memory for Where}

Project Innocence estimates that between two and five percent of people in prison have been wrongfully convicted. Juries will often attribute the provision of a false alibi to guilt; however, it is not uncommon

for people to misremember where they were. In this study, researchers will investigate people's ability to recall where they were at a given time to determine what factors influence the errors they make. The ultimate objective is to provide the legal system with a better understanding of when a faulty alibi is likely to occur and to prevent false convictions. Researchers will collect location data via Wi-Fi 
connections when participants log onto a university router. Subsequently, participants will also be asked a series of questions about where they were at certain times. Only results aggregated over many people will be released. These will appear in academic papers. All participant data will be stored in a secured server hosted by the University of Melbourne. All transmission of information across networks will occur in encrypted form. Participants will have the capacity to delete their data. Funds for the project come from the Australian Research Council Discovery Program DP312859467. Participants must opt in and will be paid $\$ 50$ for their data and $\$ 15$ for completing the memory experiment.

\section{Project Title: Serving You Better}

As part of its redevelopment of the campus, the University would like to introduce monitoring of the use of food outlets and common areas in order to understand better the factors that drive use of these facilities and how we can provide students with a better experience. A combination of technologies will be used, including thermal imaging in indoor areas to detect the presence of people and collection of data from Wi-Fi access points showing the number of devices connected and the duration of stay in an area. The data from the Wi-Fi access points will have login and device IDs removed and replaced with randomly generated IDs. This data will be analysed for statistical purposes only. No analysis of individual behaviour patterns will be undertaken. The data will be securely housed on AWS servers and analysed by University staff in conjunction with other data, such as weather and timetable data. The results will be used to inform University campus strategy, for example by identifying factors that influence the use of indoor and outdoor spaces in order to better meet future demand. The data will be made available to researchers on a case-by-case basis following ethics clearance from the University. Aggregate (i.e., not individual) data showing trends will be published as open data for reuse by the broader community. People who do not wish for their data to be stored can email the researchers for it to be deleted. 


\section{Project Title: Safe Campus}

600 In the era of \#metoo, there is growing awareness that the campus is not necessarily a safe environment 601 after dark. Academic researchers will engage with a start-up firm to develop a walking companion by

602

603

604

605

606

607

608

609

610

611

612

613

614

615

616

617

618

619

620

621

622

623

night app. The project will be funded by the Australian Research Council through their Linkage

Program. Registered users of this app will consent to be tracked continuously and to receive messages in set time windows about possible companions nearby for a real-time matching process. They also accept that their identity and location will be revealed to a matching companion, similar to a taxi service.

Twelve hours after a matched walk, the record of the identities will be deleted. The tracking data, however, will further be used for data analytics on pedestrian footfall on campus in order to make travel recommendations. The academics plan to publish their data analytics solutions and the start-up will offer an innovative service to people staying on campus.

\section{Project Title: Student Well-Being Project}

Universities are facing rising mental health problems amongst students, raising questions about whether universities are providing enough support for student emotional and mental health. As a result, the University of Melbourne is investing in a learning analytics system that will pull together different kinds of data to identify at-risk students. The system combines individual level data, such as attendance and assessment data, with aggregated (i.e., not individual) data such as location data via Wi-Fi connections when people log onto a university router. The system will generate 'flags' that are associated with events and movements that are potential signs of concern. Multiple flags will trigger an early warning alert and an intervention measure such as a meeting with a student support professional. In the first stage of the project, University of Melbourne researchers will trial and perfect the system ready for roll out next year. Researchers will access participants' personal data including attendance and assessment results, and track participant location (via their Wi-Fi connections) when they are on campus. No personal information will be released, but researchers will publish the study's findings, including a prototype 
624

625

626

627

628

629

630

631

632

633

634

635

636

637

638

639

640

641

642

643

644

645

646

647

648

system, in academic papers. All data will be stored in a secured server hosted by the University of

Melbourne for 3 years, before being destroyed. Funds for the project come from the University of

Melbourne, and participants will be paid \$20 for their participation in their study, for which they must opt in.

\section{Project Title: Move}

At particular peak times, the tram stops around campus are overcrowded. Researchers suggest improving the situation by short-term predictions of public transport demand from university timetable information, theatre occupancy data collected from the Wi-Fi network, weather data, and machine learning of correlations (patterns) over time. For this purpose, they are requesting access to location data of the population (taken via participants' Wi-Fi connections) on campus over the past year and in real-time.

Yarra Trams agrees to sponsor the research project, expecting to adapt their frequencies more flexibly to the actual demand. People, equipped with information about demand and remaining waiting times, might choose alternative transport stops, alternative modes of transport, or just decide to have a coffee first.

\section{Project Title: Project TRIIBE}

University campus shopping and food retailers currently do not have detailed information about their customers, their shopping patterns and information needs. This puts them at a disadvantage compared to online retailers who have detailed user statistics. Project TRIIBE researches methods to capture and analyse indoor shopping behaviour across shoppers physical, online and social environments, to improve customer experience. The project will collect Wi-Fi connection data and internet access history per visitor. The research team will develop privacy-aware recommendation methods based on aggregate online and physical behaviour. The project will release only a technical description of the machine learning model and a method for how a recommender system implementing this model can be 
developed, as well as the estimate of the relative significance of physical, online and social behaviours for recommendations. Only aggregate (i.e., not individual) statistical information will be released in academic papers. Users' data will be stored in an encrypted format, on a secure server and accessible only to the university research team sponsored by ARCLP792534861. Participants will be paid $\$ 100$ for their data for a month, and must opt in to participate. Industry partners will use only the developed method to improve their services, with their own data.

\section{Project Title: Project QueueSense: Measuring Queuing Behaviour}

The need to optimise the workforce and quality of service in retail, airports and front-desk services requires an efficient means to monitor queue length and service times. This project will develop methods to measure queue times based on Wi-Fi signal sensing. A few selected locations (such as café outlets) around the University will be re-configured and equipped with Wi-Fi sensing devices to collect data about customers present on premises, and the length of time spent in queues. The data collection will run over a one-month period. Only information about Wi-Fi equipped devices will be collected. Shoppers will be notified that their dwell time will be monitored while they purchase refreshments on premises through posters placed outside the cafes. Coffee will be discounted during the period of data collection. Only aggregate (i.e., not individual) statistical information will be released in academic papers. Users' data will be stored in an encrypted format, on a secure server and accessible only to the university research team sponsored by ARCLP849537612. The project is conducted with Ethics approval from the University of Melbourne. Industry partners will use only the developed method to improve their services, with their own data.

\section{Project Title: Project Fluloc: Understanding the Spread of Influenza}

Epidemiological models of influenza spread have been previously developed to predict seasonal influenza epidemics in entire nations, and more recently, in large cities. It is well documented that co- 
674 location at work and at schools contributes to the spread of the flu. This project will collect data of social 675 interactions based on indoor Wi-Fi tracking across campus to assess the role of professional and 676 educational environments in the spread of influenza. The project will collect Wi-Fi connection data per user, complemented with an online health status questionnaire to all users of the university Wi-Fi, during the flu period of 2020. The research team aim to improve epidemiological modeling methods for urban

679 680 681 682 683 684 685 686 687 688 689 690 691 692 693 694 695 696 697 698 precincts. The project will release, in academic papers, a technical description of the model and aggregate-level (i.e., not individual) statistics about the influenza season in 2020. The model will inform epidemiological management practices across educational and professional environments. Data will be stored in an encrypted format on a secure server accessible only to the university research team. The project is sponsored by the Department of Health and has Ethics approval from the University of Melbourne.

\section{Project Title: Project Precinct Change Management}

Large university campuses embedded in the urban environment are regularly impacted by large infrastructure works, such as the Metro tunnel. The ability to analyse the population dynamics on campus in a fine-grained manner would allow the university to optimise campus disturbances by reallocating space-use and making time-management and scheduling modifications for university activities. In this project, researchers will collect individual data from Wi-Fi users on campus and aggregate it to explore statistical data analytic methods enabling researchers to quantify the impact and economic cost of construction disturbances on campus operations, and research statistical optimisation methods for improved space use. This is an applied research project supported by the University Services and Facilities Management Unit. Findings of the project will directly inform operations on campus during the Metro tunnel construction and may inform further management guidelines. The research will be conducted with ethics approval from the University of Melbourne. No individual data will be released beyond a highly securitised server at the University of Melbourne. Aggregate data 
analytics will be produced in a dashboard environment for University Services and used as illustrations in publications and reports. Only aggregate-level (i.e., not individual) data will be used in publications.

\section{Project Title: The Impact of Attendance on Academic Performance}

Attendance in lectures is falling. As students juggle competing family and work commitments, the number of students appearing in class can drop 60-70\% during the period of a semester. While some lecturers are concerned that the quality of the educational outcomes that universities provide is compromised by this dynamic, others contend that online materials provide a superior student experience, especially in large classes. In this study, researchers will track a random cohort of students for one semester and analyse how much time they are spending on campus and which classes they are attending. Their location data will be cross referenced with their academic results at the end of the semester. In order to minimize the impact of selection effects, researchers will use previous academic performance to account for variation in ability between participants. Students must opt-out if they do not wish their data to be recorded. The results will be used to guide university decision-making about the relative emphasis that should be given to online and offline activities. Only aggregate (i.e., not individual) results will be published.

\section{Developing the Scenarios}

12 draft scenarios were developed by the living lab for urban mobility and adaptive space use (LUMAS) team at the University of Melbourne that described different scenarios for research use of WiFi data. These 12 scenarios were early drafts of the final scenarios presented in this paper (and one that was removed due to excessive similarity with another scenario). They were edited for simplicity of reading, length, to remove references to 'de-identified data', and to ensure there was sufficient variability in the scenarios among the final dimensions. 


\section{Developing the Privacy Dimensions}

Participants at the LUMAS workshop were placed into small groups and performed a best-worst ranking of 6 randomly drawn (of the 12) draft scenarios. Afterwards, participants discussed the various dimensions that influenced their acceptability in terms of best to worse scale and a preliminary list of relevant dimensions was made. The 12 draft scenarios were then analysed in terms of these dimensions in small groups. Afterwards, the whole group identified dimensions that they felt were relevant but were not raised by their scenarios, as well as dimensions raised by their scenarios but had not yet been captured, as well as dimensions they felt were missing.

This list of dimensions was then reduced to the final 11 dimensions to make the experiment shorter for participants and thus maximise the quality of collected data. This was done by a qualitative process in which the original dimensions were combined to higher-order or similar categories, removed when not relevant to the scenarios or too difficult to experimentally manipulate in the present experiment. This process was also informed by prior empirical and normative work which considered the dimensions or factors underlying the acceptability of tracking and surveillance ${ }^{20,21,23,24,47,48}$. Table S4 is a summary of how the 24 workshop dimensions were reduced to the 11 final dimensions.

\section{Results}

To assess the reasonableness of our assumption to treat the ordinal Likert data as numeric in our modeling, we compared the best-fitting model presented in the paper (i.e., with no interaction effects) with the same model except treating predictor variables as ordinal, and parameterizing them with monotonic effects ${ }^{49}$. The model using monotonic effects (ELPD $=-348.35, S E=18.63$ ) fit worse than the best-fitting model presented in the paper $(E L P D=-345.22, S E=17.54)$. For further details of this analysis, see https://osf.io/mx948/. 


\section{Scenario}

Work Records 安 Safe Campus Project TRIIBE Project Precinct Change Management Memory for Where Ś. Serving you Better m Project Move Project Fluloc
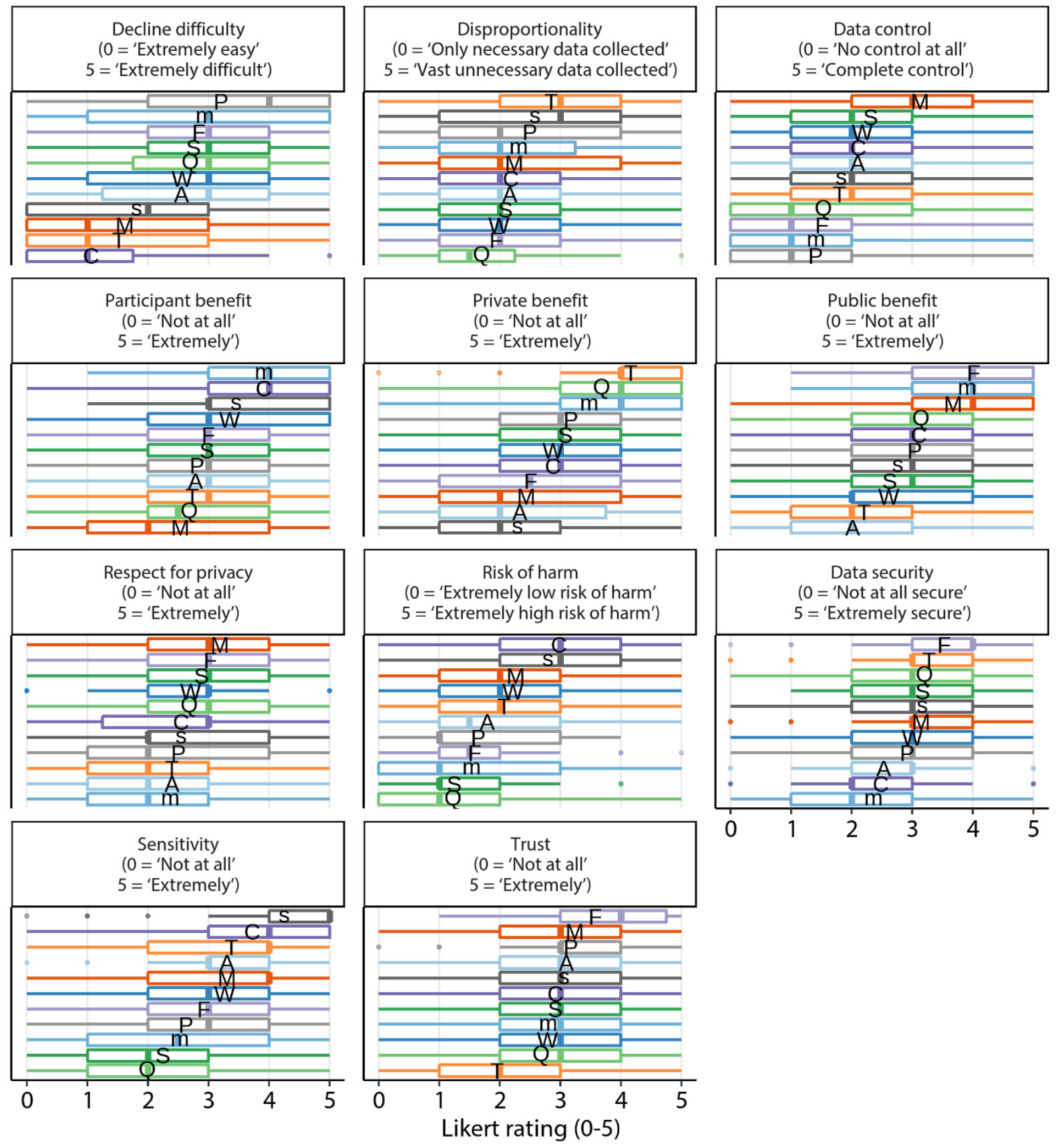

Figure S1. Participant ratings on privacy dimensions, by dimension. Participant ratings of each privacy dimension for each scenario, organised by privacy dimension. Letters on boxplots indicate the mean ratings of each privacy dimension for each scenario. 


\section{Privacy Dimension}

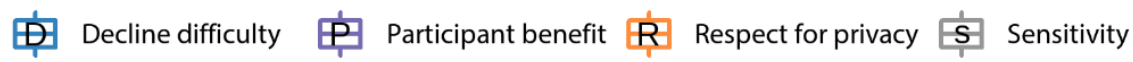

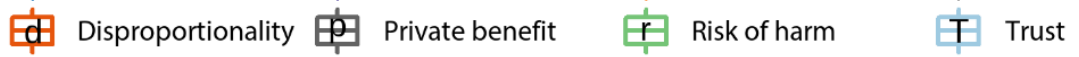

审 Data control Bitic Pubefit Sata security
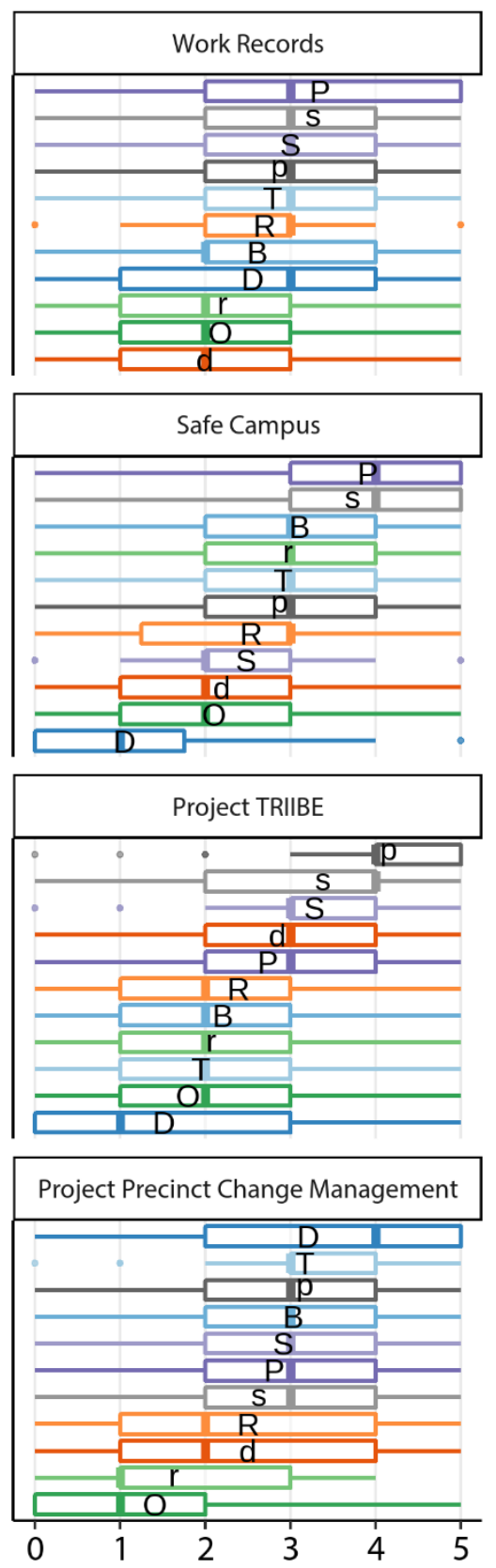

752
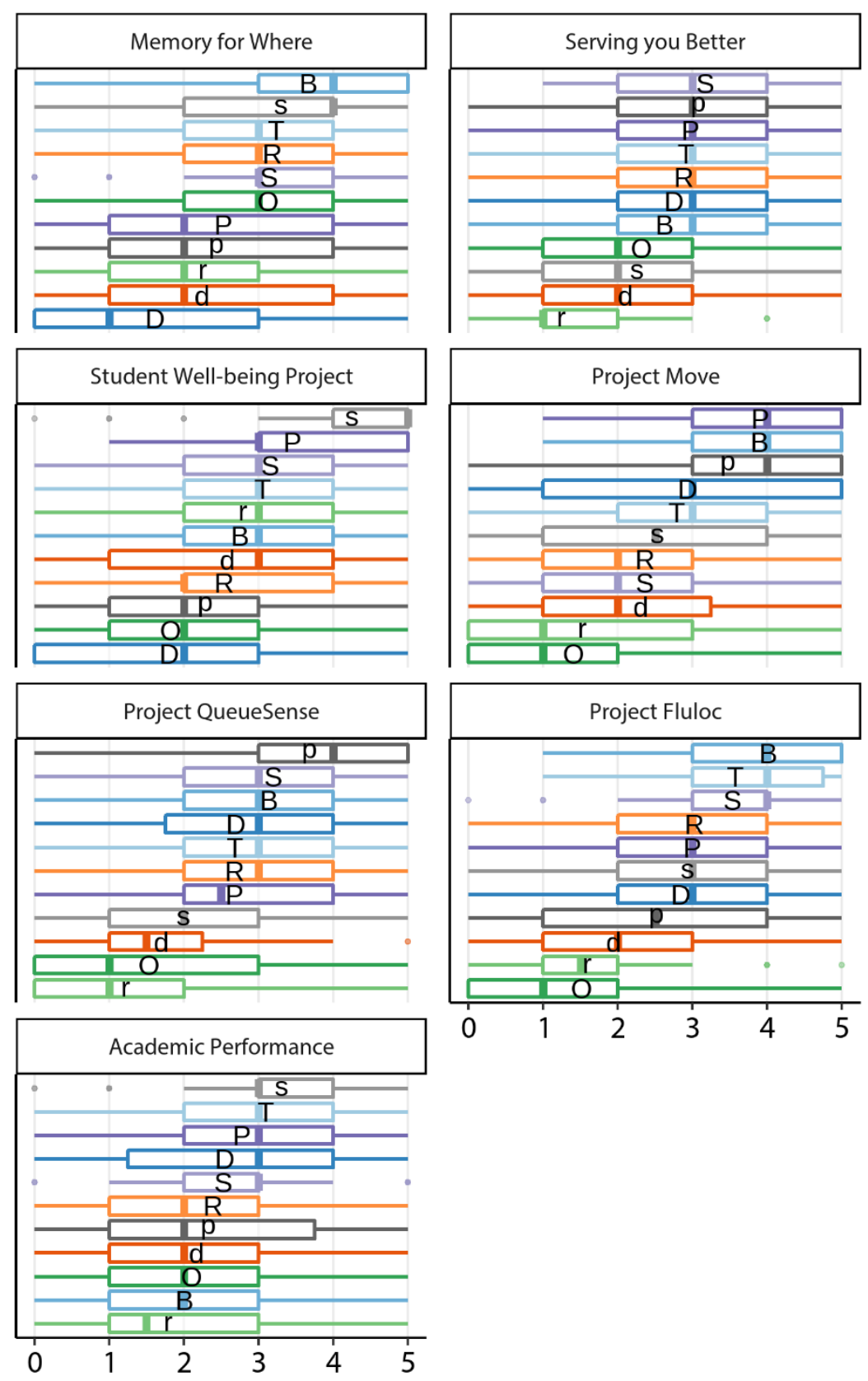

Likert rating (0-5)

Figure S2. Participant ratings on privacy dimensions, by scenario. Participant ratings of each privacy dimension for each scenario, organised by scenario. Letters on boxplots indicate the mean ratings of each privacy dimension for each scenario. 

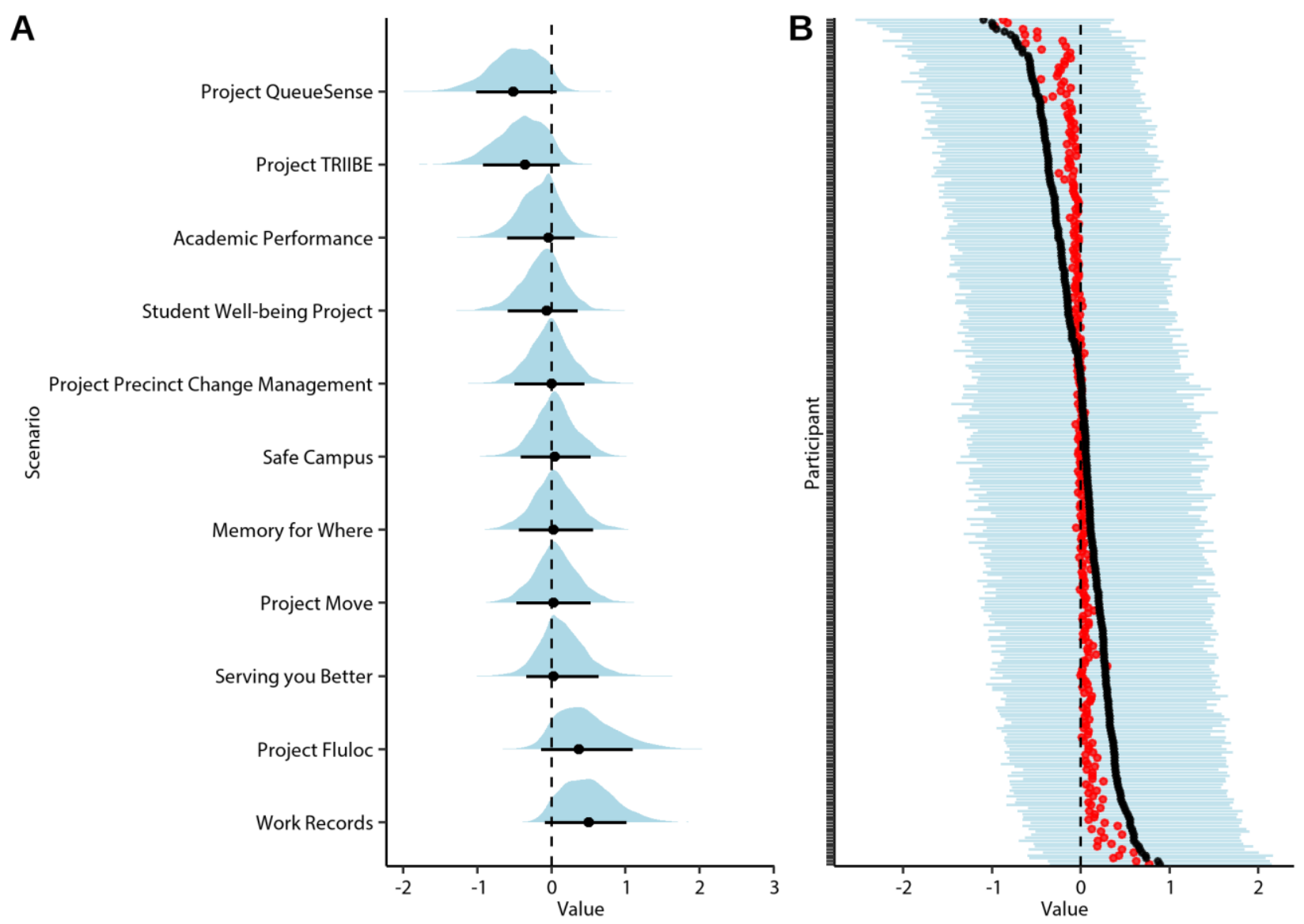

Figure S3. Random effect posterior distributions. (A) Posterior distributions of scenario random intercepts from the preferred model. Point estimates are posterior modes and intervals are $89 \%$ highest density intervals. (B) Summary of participant random intercept posterior distributions. Black point estimates are posterior means, red point estimates are posterior modes, and blue intervals are $89 \%$ highest density intervals. 


\section{Supplementary Tables}

\section{Table S1. Interaction effects included in candidate model.}

\section{A Priori Interaction Effects}

Private benefit, Participant benefit, \& Public benefit Private benefit \& Participant benefit

Private benefit \& Public benefit

Participant benefit \& Public benefit

Risk of harm \& Decline difficulty

Risk of harm \& Ongoing control

Security \& Sensitivity

Sensitivity \& Ongoing control

Trust \& Sensitivity

Trust \& Risk of harm

Trust \& Security 
Table S2. Parameter posterior distribution summary statistics for model parameters.

\begin{tabular}{|c|c|c|c|c|c|}
\hline Parameter & Mode & $\exp ($ mode $)$ & $89 \% \mathrm{HDI}$ & $\begin{array}{c}\% \text { HDI in } \\
\text { ROPE }\end{array}$ & Rhat \\
\hline Intercept & -1.55 & NA & {$[-2.64,-0.52]$} & NA & 1.00 \\
\hline Decline Difficulty & -0.05 & 0.95 & {$[-0.17,0.04]$} & 74.3 & 1.00 \\
\hline Private Benefit & -0.04 & 0.96 & {$[-0.17,0.06]$} & 79.44 & 1.00 \\
\hline Participant Benefit & 0.26 & 1.29 & {$[0.14,0.42]$} & 0 & 1.00 \\
\hline Public Benefit & 0.14 & 1.15 & {$[0.01,0.29]$} & 26.93 & 1.00 \\
\hline Disproportionality & -0.09 & 0.93 & {$[-0.22,0.04]$} & 56.02 & 1.00 \\
\hline Sensitivity & -0.24 & 0.78 & {$[-0.43,-0.10]$} & 0 & 1.00 \\
\hline Risk of Harm & -0.29 & 0.75 & {$[-0.45,-0.14]$} & 0 & 1.00 \\
\hline Trust & 0.49 & 1.63 & {$[0.34,0.68]$} & 0 & 1.00 \\
\hline Data Security & 0.12 & 1.13 & {$[-0.01,0.30]$} & 32.01 & 1.00 \\
\hline Ongoing Control & 0.21 & 1.23 & {$[0.08,0.36]$} & 3.54 & 1.00 \\
\hline Respect for Privacy & 0.54 & 1.72 & {$[0.36,0.70]$} & 0 & 1.00 \\
\hline Scenario random intercept $S D$ & 0.42 & NA & {$[0.11,0.78]$} & NA & 1.00 \\
\hline Participant random intercept $S D$ & 0.86 & NA & {$[0.40,1.28]$} & NA & 1.01 \\
\hline
\end{tabular}

Note. $R O P E=$ Region of practical equivalence, $H D I=$ Highest density interval, $N=861$. 
Table S3. Parameter coefficients for predictive model.

\begin{tabular}{lc}
\hline Parameter & Coefficient \\
\hline Intercept & -1.36 \\
Decline Difficulty & -0.15 \\
Private Benefit & -0.12 \\
Participant Benefit & 0.27 \\
Public Benefit & 0.11 \\
Disproportionality & -0.06 \\
Sensitivity & -0.32 \\
Risk of Harm & -0.31 \\
Trust & 0.55 \\
Data Security & 0.32 \\
Ongoing Control & 0.18 \\
\hline
\end{tabular}


Table S4. Developing final privacy dimensions from workshop dimensions.

Dimension from LUMAS workshop

Opt-in/opt-out

Transparency

Commercial v Non-commercial benefit

Personal Benefit

Who Benefits? How Much?

Public Benefit v Private Benefit

Benefit Sharing

Training and Capacity Building

Proportionality

Scope of Data

Risk of Harm

Sensitivity

Bona fide

Track record

Conflict of interest

Evaluation and monitoring

\section{Equality}

Security

Use/Reuse/Retention

Ongoing Subject control

Where/What results released

Licensing

Data Linkage
Notes re conversion to final dimensions
Removed because is difficult to rate from scenario descriptions.
Combined in final dimensions as 'Participant Benefit', 'Private Benefit', and 'Public Benefit'.

Combined in final dimensions as 'Disproportionality'.

Retained.

Retained.

Combined in final dimensions as 'Trust'.

Removed because is difficult to determine empirically and is hard to define clearly in survey.

Retained in final dimensions as 'Data Security'.

Retained.

Removed as no variability among scenarios. In each, only aggregate information was to be released, and this is generally the case for university research.

Removed because not used in scenarios, and unlikely to be understood by the general population.

Subsumed under 'Risk of Harm' dimension.

'Respect for Privacy' dimension added after literature review. 